\title{
Front Matter: Volume 7033
}

, "Front Matter: Volume 7033," Proc. SPIE 7033, Plasmonics: Nanoimaging, Nanofabrication, and Their Applications IV, 703301 (29 September 2008); doi: $10.1117 / 12.806028$

SPIE Event: NanoScience + Engineering, 2008, San Diego, California, United SPIE. States 


\section{PROCEEDINGS OF SPIE}

\section{Plasmonics: Nanoimaging, Nanofabrication, and Their Applications IV}

Satoshi Kawata

Vladimir M. Shalaev

Din Ping Tsai

Editors

10-14 August 2008

San Diego, California, USA

Sponsored and Published by

SPIE

Volume 7033 
The papers included in this volume were part of the technical conference cited on the cover and title page. Papers were selected and subject to review by the editors and conference program committee. Some conference presentations may not be available for publication. The papers published in these proceedings reflect the work and thoughts of the authors and are published herein as submitted. The publisher is not responsible for the validity of the information or for any outcomes resulting from reliance thereon.

Please use the following format to cite material from this book:

Author(s), "Title of Paper," in Plasmonics: Nanoimaging, Nanofabrication, and Their Applications IV, edited by Satoshi Kawata, Vladimir M. Shalaev, Din Ping Tsai, Proceedings of SPIE Vol. 7033 (SPIE, Bellingham, WA, 2008) Article CID Number.

ISSN 0277-786X

ISBN 9780819472533

Published by

SPIE

P.O. Box 10, Bellingham, Washington 98227-0010 USA

Telephone +1 3606763290 (Pacific Time) · Fax +1 3606471445

SPIE.org

Copyright (c) 2008, Society of Photo-Optical Instrumentation Engineers

Copying of material in this book for internal or personal use, or for the internal or personal use of specific clients, beyond the fair use provisions granted by the U.S. Copyright Law is authorized by SPIE subject to payment of copying fees. The Transactional Reporting Service base fee for this volume is $\$ 18.00$ per article (or portion thereof), which should be paid directly to the Copyright Clearance Center (CCC), 222 Rosewood Drive, Danvers, MA 01923. Payment may also be made electronically through CCC Online at copyright.com. Other copying for republication, resale, advertising or promotion, or any form of systematic or multiple reproduction of any material in this book is prohibited except with permission in writing from the publisher. The CCC fee code is $0277-786 \mathrm{X} / 08 / \$ 18.00$.

Printed in the United States of America.

Publication of record for individual papers is online in the SPIE Digital Library.

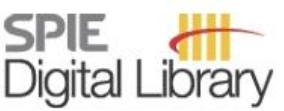

SPIEDigitalLibrary.org

Paper Numbering: Proceedings of SPIE follow an e-First publication model, with papers published first online and then in print and on CD-ROM. Papers are published as they are submitted and meet publication criteria. A unique, consistent, permanent citation identifier (CID) number is assigned to each article at the time of the first publication. Utilization of CIDs allows articles to be fully citable as soon they are published online, and connects the same identifier to all online, print, and electronic versions of the publication. SPIE uses a six-digit CID article numbering system in which:

- The first four digits correspond to the SPIE volume number.

- The last two digits indicate publication order within the volume using a Base 36 numbering system employing both numerals and letters. These two-number sets start with 00, 01, 02, 03, 04, 05, $06,07,08,09,0 \mathrm{~A}, 0 \mathrm{~B} \ldots \mathrm{OZ}$, followed by $10-1 \mathrm{Z}, 20-2 \mathrm{Z}$, etc.

The CID number appears on each page of the manuscript. The complete citation is used on the first page, and an abbreviated version on subsequent pages. Numbers in the index correspond to the last two digits of the six-digit CID number. 


\section{Contents}

vii Conference Committee

xi Introduction

xiii Revivals of molecular nonlinear optics in physics, chemistry, and life sciences (Plenary Paper) [7040-100]

J. Zyss, Lab. de Photonique Quantique et Moléculaire, CNRS, Institut d'Alembert (France)

\section{NANOFABRICATION AND LITHOGRAPHY}

703305 Hierarchical architectures based on optical near-field interactions (Invited Paper) [7033-04]

N. Tate, W. Nomura, Univ. of Tokyo (Japan); T. Yatsui, Japan Science and Technology Agency (Japan); M. Naruse, Univ. of Tokyo (Japan) and National Institute of Information and Communications Technology (Japan); M. Ohtsu, Univ. of Tokyo (Japan)

703306 Photochemical nano-scale patterning with Rhodamine 6G dye from aqueous phase [7033-05]

A. Kassu, F. A. Calzzani, Jr., J. M. Taguenang, R. K. Sileshi, A. Sharma, Alabama A\&M Univ. (United States)

\section{PLASMONIC SPECTROSCOPY II}

7033 OC Highly efficient heating assisted tip-enhanced Raman spectroscopy [7033-11]

A. Tarun, RIKEN, The Institute of Physical and Chemical Research (Japan); N. Hayazawa, RIKEN, The Institute of Physical and Chemical Research (Japan) and CREST, Japan Science and Technology Agency (Japan); M. Motohashi, Osaka Univ. (Japan); S. Kawata, RIKEN, The Institute of Physical and Chemical Research (Japan), Osaka Univ. (Japan), and CREST, Japan Science and Technology Agency (Japan)

\section{NANO-IMAGING I}

7033 OE Ultra-high resolution Raman imaging by optically trapped dielectric microsphere (Invited Paper) [7033-13]

Z. X. Shen, J. Kasim, Nanyang Technological Univ. (Singapore)

\section{NANO-IMAGING II}

7033 ol Nanoscale coupling effects on single particle microscopy (Invited Paper) [7033-17]

K. L. Shuford, K. A. Meyer, Oak Ridge National Lab. (United States); C. Li, S. O. Cho, Korea Advanced Institute of Science and Technology (Korea, Republic of); W. B. Whitten, R. W. Shaw, Oak Ridge National Lab. (United States) 
703300 Self-assembled monolayers on gold nanospheres studied by optical second-harmonic generation [7033-23]

T. Yamaguchi, K. Kajikawa, Tokyo Institute of Technology (Japan)

MANIPULATION OF PLASMONIC EFFECTS I

7033 OR Nanoplasmonics in near-field optics and active coupling (Invited Paper) [7033-26]

M. C. Quong, A. Y. Elezzabi, Univ. of Alberta (Canada)

7033 OS Surface plasmon routing in dielectric-loaded surface plasmon polariton waveguides (Invited Paper) [7033-27]

J. Grandidier, S. Massenot, A. Bouhelier, G. Colas des Francs, J.-C. Weeber, L. Markey,

A. Dereux, Institute Carnot de Bourgogne, UMR 5209 CNRS, Univ. de Bourgogne (France)

7033 OT Nanophotonic components utilizing channel plasmon polaritons (Invited Paper) [7033-28]

V. S. Volkov, S. I. Bozhevolnyi, Univ. of Southern Denmark (Denmark); E. Devaux, J.-Y. Laluet,

T. W. Ebbesen, Lab. des Nanostructures, ISIS, Univ. Louis Pasteur (France)

\section{MANIPULATION OF PLASMONIC EFFECTS II}

7033 OV Plasmonic waveguides with wavelength selective function (Invited Paper) [7033-30] M. Haraguchi, Y. Matsuzaki, T. Tsuzura, T. Okamoto, M. Fukui, The Univ. of Tokushima (Japan); K. Okamoto, S. Seki, S. Tagawa, Osaka Univ. (Japan)

7033 OW Terahertz propagation in structured metals (Invited Paper) [7033-31]

M. Hangyo, K. Takano, K. Shibuya, Osaka Univ. (Japan); F. Miyamaru, Shinshu Univ. (Japan): H. Miyazaki, Tohoku Univ. (Japan)

\section{MANIPULATION OF PLASMONIC EFFECTS III}

7033 OY Efficient transmission through a plasmonic T-branch with a mesa structure in metal gap optical waveguides [7033-33]

J. Takahara, M. Nishimori, T. Nagatsuma, Osaka Univ. (Japan)

\section{PLASMONICS I}

703311 Dephasing of electromagnetic fields in scattering from an isolated slit in a gold film (Invited Paper) [7033-36]

J. M. McMahon, Northwestern Univ. (United States) and Argonne National Lab. (United States); S. K. Gray, Argonne National Lab. (United States); G. C. Schatz, Northwestern Univ. (United States) 
703319 Surface plasmon resonance linear and nonlinear response in a single nanorod (Invited Paper) [7033-44]

H. Baida, D. Christofilos, P. Maioli, A. Crut, N. Del Fatti, F. Vallée, LASIM, Univ. de Lyon, CNRS (France)

7033 1B Surface plasmon polariton detection discriminating polarization-dependent image dipole effects [7033-46]

K. G. Lee, K. J. Ahn, H. W. Kihm, J. S. Ahn, D. S. Kim, Seoul National Univ. (South Korea)

\section{PLASMONIC MATERIALS II}

7033 1D Controlling the optical transparency of meta-materials with a strong DC magnetic field (Invited Paper) [7033-48]

Y. M. Strelniker, Bar-Ilan Univ. (Israel); D. J. Bergman, Tel Aviv Univ. (Israel)

7033 IE Thermal emission from metallic films perforated with subwavelength hole arrays (Invited Paper) [7033-49]

M. Diwekar, T. Matsui, A. Agrawal, A. Nahata, Z. V. Vardeny, Univ. of Utah (United States)

\section{PLASMONIC MATERIALS III}

7033 1H Plasmonic metamaterials and their applications in novel terahertz devices (Invited Paper) [7033-52]

T. Otsuji, Tohoku Univ. (Japan)

$703311 \quad$ Plasmonic metamaterials and their applications (Invited Paper) [7033-53]

I. I. Smolyaninov, BAE Systems (United States)

\section{NANOPLASMONIC APPLICATIONS I}

7033 iN Controlled thermal emission of two-color polarized infrared light from arrayed plasmon nanocavities (Invited Paper) [7033-58]

K. Ikeda, Nalux Co., Ltd. (Japan); H. T. Miyazaki, T. Kasaya, National Institute for Materials

Science (Japan); K. Yamamoto, Y. Inove, K. Fujimura, T. Kanakugi, Nalux Co., Ltd. (Japan)

\section{NANOPLASMONIC APPLICATIONS II}

7033 IP Nanoscale surface-emitting semiconductor plasmon lasers (Invited Paper) [7033-60]

C. Manolatou, F. Rana, Cornell Univ. (United States)

$70331 Q \quad$ The strength of surface plasmons (Invited Paper) [7033-61]

M. Righini, Institut de Ciencies Fotoniques (Spain); C. Girard, CEMES, UPR, CNRS 8011

(France); R. Quidant, Institut de Ciencies Fotoniques (Spain) and Institució Catalana de Recerca i Estudis Avançats (Spain) 
7033 is Reflectivity of a glass thin film with different nanostructures (Invited Paper) [7033-63]

H. Wang, S. Zou, Univ. of Central Florida (United States)

\section{NANOPLASMONIC APPLICATIONS IV}

7033 IV Plasmonic nanoparticle scattering for enhanced performance of photovoltaic and photodetector devices (Invited Paper) [7033-66]

E. T. Yu, D. Derkacs, S. H. Lim, P. Matheu, D. M. Schaadt, Univ. of California, San Diego (United States)

7033 1X Experimental measurement of surface plasmon resonance of pyramidal metal nanoparticle tips [7033-68]

Y. Zou, K. B. Crozier, Harvard School of Engineering and Applied Sciences (United States)

7033 IY Surface plasmons modulate the spatial coherence of light in Young's interference experiment [7033-69]

C. H. Gan, G. J. Gbur, Univ. of North Carolina at Charlotte (United States); T. D. Visser, Free Univ. Amsterdam (Netherlands)

703312 Optimization of dichroism in laser-induced transformation of silver nanoparticles in glass [7033-70]

A. Stalmashonak, Akin A. Unal, G. Seifert, H. Graener, Martin-Luther-Univ. Halle-Wittenberg (Germany)

\section{POSTER SESSION}

703323 Variable-focusing surface plasmon dielectric lens using air-gap modulation [7033-74] J. Park, H. Kim, J. Hahn, B. Lee, Seoul National Univ. (South Korea)

703324 Linear and nonlinear optical properties of aggregated spherical gold nanoparticles [7033-76]

A. Sato, Tokyo Institute of Technology (Japan); K. Tsuboi, PRESTO, Japan Science and Technology Agency (Japan); T. Yamaguchi, Tokyo Institute of Technology (Japan); K. Kajikawa, Tokyo Institute of Technology (Japan) and PRESTO, Japan Science and Technology Agency (Japan)

703329 Localized surface plasmon microscope employing a beam scanning method [7033-82] K. Watanabe, G. Terakado, H. Kano, Muroran Institute of Technology (Japan) 


\title{
Conference Committee
}

\author{
Symposium Chairs
}

David L. Andrews, University of East Anglia Norwich (United Kingdom) James G. Grote, Air Force Research Laboratory (United States)

Kevin J. Liddane, Oerlikon Optics USA Inc. (United States)

Conference Chairs

Satoshi Kawata, Osaka University (Japan)

Vladimir M. Shalaev, Purdue University (United States)

Din Ping Tsai, National Taiwan University (Taiwan)

Program Committee

Harry A. Atwater, Jr., California Institute of Technology (United States)

David J. Bergman, Tel Aviv University (Israel)

Sergey I. Bozhevolnyi, Aalborg Universitet (Denmark)

Nader Engheta, University of Pennsylvania (United States)

Jochen Feldmann, Ludwig-Maximilians-Universität München

(Germany)

Naomi J. Halas, Rice University (United States)

Teruya Ishihara, RIKEN (Japan)

Fritz Keilmann, Max-Planck-Institut für Biochemie (Germany)

Pieter G. Kik, College of Optics \& Photonics, University of Central

Florida (United States)

Victor I. Klimov, Los Alamos National Laboratory (United States)

Joachim R. Krenn, Karl-Franzens-Universität Graz (Austria)

Aaron Lewis, The Hebrew Universityof Jerusalem (Israel)

Olivier J. F. Martin, École Polytechnique Fédérale de Lausanne

(Switzerland)

Martin Moskovits, University of California, Santa Barbara (United States)

Peter J. Nordlander, Rice University (United States)

Masaya Notomi, NTT Basic Research Laboratories (Japan)

Lukas Novotny, University of Rochester (United States)

Motoichi Ohtsu, The University of Tokyo (Japan)

Joseph W. Perry, Georgia Institute of Technology (United States)

Lewis J. Rothberg, University of Rochester (United States)

Vahid Sandoghdar, ETH Zürich (Switzerland)

George C. Schatz, Northwestern University (United States)

Tigran V. Shahbazyan, Jackson State University (United States)

Mark I. Stockman, Georgia State University (United States)

Xiang Zhang, University of California, Berkeley (United States)

Nikolay I. Zheludev, University of Southampton (United Kingdom) 
Session Chairs

1 Nanofabrication and Lithography

Thomas A. Klar, Ludwig-Maximilians-Universität München (Germany)

2 Plasmonic Spectroscopy I

Yuh-Lin Wang, Academia Sinica (Taiwan)

3 Plasmonic Spectroscopy II

Yuh-Lin Wang, Academia Sinica (Taiwan)

$4 \quad$ Nano-imaging I

Satoshi Kawata, Osaka University (Japan)

5 Nano-imaging II

Ze Xiang Shen, Nanyang Technological University (Singapore)

$6 \quad$ Nanosensing

Teri W. Odom, Northwestern University (United States)

7 Manipulation of Plasmonic Effects I

Vladimir M. Shalaev, Purdue University (United States)

8 Manipulation of Plasmonic Effects II

Stefan A. Maier, Imperial College London (United Kingdom)

9 Manipulation of Plasmonic Effects III

George C. Schatz, Northwestern University (United States)

10 Plasmonics 1

Che Ting Chan, Hong Kong University of Science and Technology (Hong Kong China)

11 Plasmonics $\|$

Hirokazu Hori, University of Yamanashi (Japan)

12 Plasmonic Materials I

Pieter G. Kik, College of Optics \& Photonics, University of Central Florida (United States)

13 Plasmonic Materials II

Pieter G. Kik, College of Optics \& Photonics, University of Central Florida (United States)

14 Plasmonic Materials III

Nader Engheta, University of Pennsylvania (United States) 
15 Nanoplasmonic Applications I

Xiang Zhang, University of California, Berkeley (United States)

16 Nanoplasmonic Applications II

Naomi J. Halas, Rice University (United States)

17 Nanoplasmonic Applications III

Prabhat Verma, Osaka University (Japan)

18 Nanoplasmonic Applications IV

Din Ping Tsai, National Taiwan University (Taiwan) 
Downloaded From: https://www.spiedigitallibrary.org/conference-proceedings-of-spie on 26 Apr 2023

Terms of Use: https://www.spiedigitallibrary.org/terms-of-use 


\section{Introduction}

This proceedings contains papers presented at the 2008 SPIE Optics \& Photonics conference titled Plasmonics: Nanoimaging, Nanofabrication, and Their Applications IV, held in San Diego, California, 10-14 August 2008. The aim of the conference was to bring together specialists from diverse research areas and to provide a forum for the exchange of information on latest progress of plasmonics, to accelerate their applications, and to look at the directions in which research in this field is leading us.

The conference and proceedings have been divided into 18 sessions. In the first session, papers are related to nanofabrication and lithography, such as designing hierarchical plasmonic materials, fabrication of metallic nanostructures with combination of laser nanolithography and selected surface metallization, fabricating plasmonic components for nanophotonics, and parallel architecture based on optical near-field interaction.

The second and third sessions are on plasmonic spectroscopy, including surfaceenhanced Raman spectroscopy on nanolithography-prepared substrates, plasmonic interactions in surface-enhanced spectroscopy and microscopy, nanoscale characterization and spectroscopy of strained silicon, and probing the plasmonic local density of states with electron energy loss spectroscopy. The fourth and fifth sessions focus on nano-imaging, specifically on attosecond nanoplasmonic field microscope, ultrahigh resolution Raman imaging by optically trapped dielectric microsphere, nanofocusing and dispersion control in plamonic waveguides, nanoscale coupling effects on single particle microscopy, and imaging with a nanohole array.

The sixth session is on nanosensing. Plasmon hybridization at medal nanostructures as a route to sensitive optical detection was reported. The seventh, eighth, and ninth sessions deal with manipulation of plasmonic effects. Spectral and spatial mode engineering of plasmonic cavities and waveguides, nanoplasmonics in near-field optics and active coupling, integrated surface plasmon routing, nanophotonic components utilizing channel plasmon polaritons, surface plasmon generation and detection with integrated organic semiconductor devices, plasmonic waveguides with wavelength selective function, terahertz wave propagation in structured metals, and near-field optical phase antennas or longrange plasmon coupling were presented.

The tenth and eleventh sessions are on plasmonics, especially on nanoparticle optical property modeling, metallic nanoparticle arrays: a common substrate for both SERS and SEIRA, plasmonic coupling of silver nanoparticle arrays with sub10nm gaps, beyond gold nanospheres for plasmonic applications, light-induced forces in plasmonic spheres, cooperative plasmon-mediated fluorescence near a 
metal nanoparticle, surface plasmons, absorption and emission in gold-silica-dye hybrid nanoparticles, and surface plasmon resonance linear and nonlinear response in a single metal nanoparticle.

The twelfth, thirteenth, and fourteenth sessions are related to plasmonic materials, including color-imaging through plasmonic nanolens, controlling of the optical transparency of meta-materials with a strong DC magnetic field, optical studies of plasmonic matematerials, between the looking-glasses: negative refraction, superlensing, and field-effect modulation in metal-insulator-metal waveguides, squeezing optical signals through epsilon-near-zero plasmonic channels, plasmonic metamaterials and their applications in novel terahertz devices, and plasmonic metamaterials and their applications.

The fifteenth to eighteenth sessions are devoted to nanoplasmonic applications, including engineered surface plasmon resonances for biodetection, intergrated photonics and non-linear optics, design and fabrication of micro/nanoscale plasmonic waveguide devices aimed for VLSI photonic circuit application, configuration and evaluation of nanophotonics devices and systems, gold nanostoves, controlled thermal emission of two-color polarized infrared light from arrayed plasmon nanocavities, nanoscale surface-emitting semiconductor plasmon lasers, the strength of surface plasmons, harnessing the photothermal response of plasmonic nanostructure for actuation applications: expanding options in cancer therapy, reduced scattering of a nanostructured particle of film, and plasmonic nanoparticle scattering for enhanced performance photovoltaic and photodetector devices.

However, please notice that some of the papers presented at the conference were published elsewhere; therefore, these proceedings only include partial contributions of the conference.

\section{Satoshi Kawata Vladimir M. Shalaev Din Ping Tsai}

